\title{
Cymbasoma tumorifrons (Copepoda: Monstrilloida): An Expanded Description Based on a New Collection from the Eastern Tropical Pacific ${ }^{1}$
}

\author{
E. Suárez-Morales ${ }^{2,3}$ and C. Alvarez-Silva ${ }^{4}$
}

\begin{abstract}
A female of the monstrilloid copepod species Cymbasoma tumorifrons (Isaac, 1975), previously known only from the Aegean Sea, was recorded in a bay of the Mexican tropical Pacific. The female of this rare species has not been recorded since its description more than $25 \mathrm{yr}$ ago. To complement the brief original description, an expanded description and illustrations of this species are presented here based mainly on the Mexican specimen but considering also type material. Standards recently set for description of monstrilloid copepods were followed. Several characters such as chaetotaxy of legs $1-4$, details of the antennular armature, cuticular ornamentation, and the fifth legs were overlooked in the original diagnosis and are described and analyzed here. This record supports an important range extension of the known distribution of this species from the Mediterranean Sea to the Mexican Pacific. It represents only the fourth record of a Cymbasoma species in the eastern Pacific.
\end{abstract}

Monstrilloid copepods are parasites of polychaetes and mollusks during most of their life cycle. Only adults and early larval stages are free-living, planktonic, and nonfeeding. Adults are exclusively reproductive individuals (Isaac 1975). The lack of oral appendages is one of the main morphologic features of this rare group. Hence, their taxonomy is based on a limited set of characters. Inadequate descriptions in early works on Monstrilloida has led to complex taxonomic problems (Grygier 1994). Most of the problems were caused by an imprecise knowledge or understanding of monstrilloid morphology.

In 1974 and 1975, Michael J. Isaac described several species of this group of copepods from different parts of the world. Most of these descriptions are now considered to

${ }^{1}$ Manuscript accepted 9 August 2000.

2 El Colegio de la Frontera Sur (ECOSUR-Chetumal), A.P. 424, Chetumal, Quintana Roo 77000, México.

3 Author for correspondence.

${ }^{4}$ Universidad Autónoma Metropolitana-Iztapalapa, Departamento de Hidrobiología, A.P. 55-535, México, D.F., México.

Pacific Science (2001), vol. 55, no. 2:183-189

(C) 2001 by University of Hawai'i Press.

All rights reserved be incomplete according to current standards, mainly because relevant taxonomic characters were not mentioned. Several of the species he described have been redescribed, adding more taxonomic details (Suárez-Morales and Riccardi 1997, Suárez-Morales 1999). A redescription of male $C$. tumorifrons was recently published by Suárez-Morales (1999) based on the type material. In this paper we expand the brief description and draft illustrations of female C. tumorifrons published by Isaac (1974) by providing more detail: descriptions of the swimming legs, details of antennular armature and the fifth legs, and features of the cuticular ornamentation.

\section{MATERIALS AND METHODS}

Type specimens of Cymbasoma tumorifrons were requested for reexamination from the Copepoda collection of the British Museum of Natural History, London. Six specimens, three males and three females, of C. tumorifrons collected at Emborios Bay, Aegean Sea, Greece, on 8 August 1967 were sent to E.S.-M.

Zooplankton material collected in Zihuatanejo Bay, Mexican Pacific, yielded a female assignable to $C$. tumorifrons. The type females of this species were compared with the Mexi- 
can specimen and new morphological data added in compliance with the new standards set by Grygier and Ohtsuka (1995) for description of monstrilloid copepods.

\section{RESULTS AND DISCUSSION}

Order Monstrilloida Sars, 1903

Cymbasoma tumorifrons (Isaac, 1975)

Figures 1-5, 6-14

DESCRIPTION OF MEXICAN MATERIAL: Female. Total body length (measured in dorsal view from anterior end of cephalothorax to posterior margin of anal somite) of Mexican specimen: $1.4 \mathrm{~mm}$. Cephalothorax relatively short and broad, representing slightly more than $55 \%$ of total body length (Figures $1,2,6)$. Oral papilla moderately protuberant, distally subquadrate, located $25 \%$ of way back along ventral surface of cephalothorax (Figures 3,6). Cephalic region wide, tapering abruptly toward posterior end; anterior margin of head slightly rounded, with low, domed forehead with rugose margin. Two relatively long sensillae on top of forehead margin, strongly sclerotized area present around bases of sensillae (Figure 5). Ocelli present, pigment cups large, very close to each other, barely separated by a distance less than $20 \%$ the diameter of the cup. Eyes almost unpigmented, round in dorsal view, asymmetrically arranged as seen in dorsal and ventral views (Figures 1, 2).

Cephalothorax widest at anterior onethird, very lightly ornamented, with faint transverse lines but with zones of denser chitinized lines and ridges, particularly on the dorsal surface of the head, clearly distinguishable in lateral view (Figure 3). Cuticular striations present ventrally around the oral papilla, and on opposite dorsal surface. Two pairs of nipplelike ornamentations present on ventral surface of cephalothorax between antennular bases and oral papilla (Figure 3), anteriormost pair larger, with a more complex ridge pattern than smaller posterior pair.

Antennules relatively short and strong, $0.25 \mathrm{~mm}$ long (measured from base of first segment), representing almost $18 \%$ of total body length, and ca. $31 \%$ as long as cephalothorax, with only two apparent segments, purported segments 2-4 exhibited by most females of the genus fused, demarcated by constrictions along margin (Figure 4, broad arrows). Length ratio of antennular segments considering fusion: $14.3: 85.7=100$, and considering all four purported segments (proximal to distal): $14.3: 32.4: 10.8: 42.5=$ 100 (Figure 4). Following setal nomenclature proposed by Grygier and Ohtsuka (1995) for female monstrilloid copepod antennules, the pattern shown by this specimen is quite well developed: the complete set is present on the first (1), second $\left(2 \mathrm{v}_{1-3}, 2 \mathrm{~d}_{1,2}\right.$, IId), and third (IIIv, 3, IIId) segments. Other elements frequently lost or absent in other species and even in other specimens of $C$. tumorifrons, such as aesthetasc 4aes and spines $4 v_{1-3}$ and $4 d_{1,2}$, are clearly present on the fourth segment; seta $\mathrm{V}_{\mathrm{v}}$ below, not between setae $\mathrm{Vd}$ and Vm. Aesthetasc 6aes very strongly developed (see Figure 4).

First pedigerous thoracic somite incorporated into cephalothorax. This and succeeding three pedigers each bearing well-developed swimming legs, all with triarticulate endopodites and exopodites and with same armament pattern, except for leg 1 exopodite, with one seta fewer on distal segment than in other legs (Figure 11). Exopods longer than endopods in legs 1-4. Coxae of each pair joined by rectangular coupler, about 1.8 times longer than wide. Basis wide and massive in anterior view, narrow laterally, separated from coxa by diagonal articulation on anterior face. Outer margin of basis of swimming legs 1, 2, and 4 with small, thin seta; seta in this position on leg 3 more than 3 times longer than in other legs (Figures 13, 14). All natatory setae lightly and biserially plumose, outer distal exopod spiniform seta armed with continuous row of small spinules on outer margin, sparsely and lightly setulated from proximal one-fifth along inner margin (Figures 11, 12). Armament formula of swimming legs as follows: leg 1 : basis, $0-1$; exopod, I-1;0-1;I,2,2; endopod, 0-1;0-1;1,2,2; legs 2-4: basis, $0-1$; exopod, I- $0 ; 0-1 ; \mathrm{I}, 2,3$; endopod, $0-1 ; 0-1 ; 1,2,2$. Fifth leg consisting of single ramus, widely divergent, tapering 

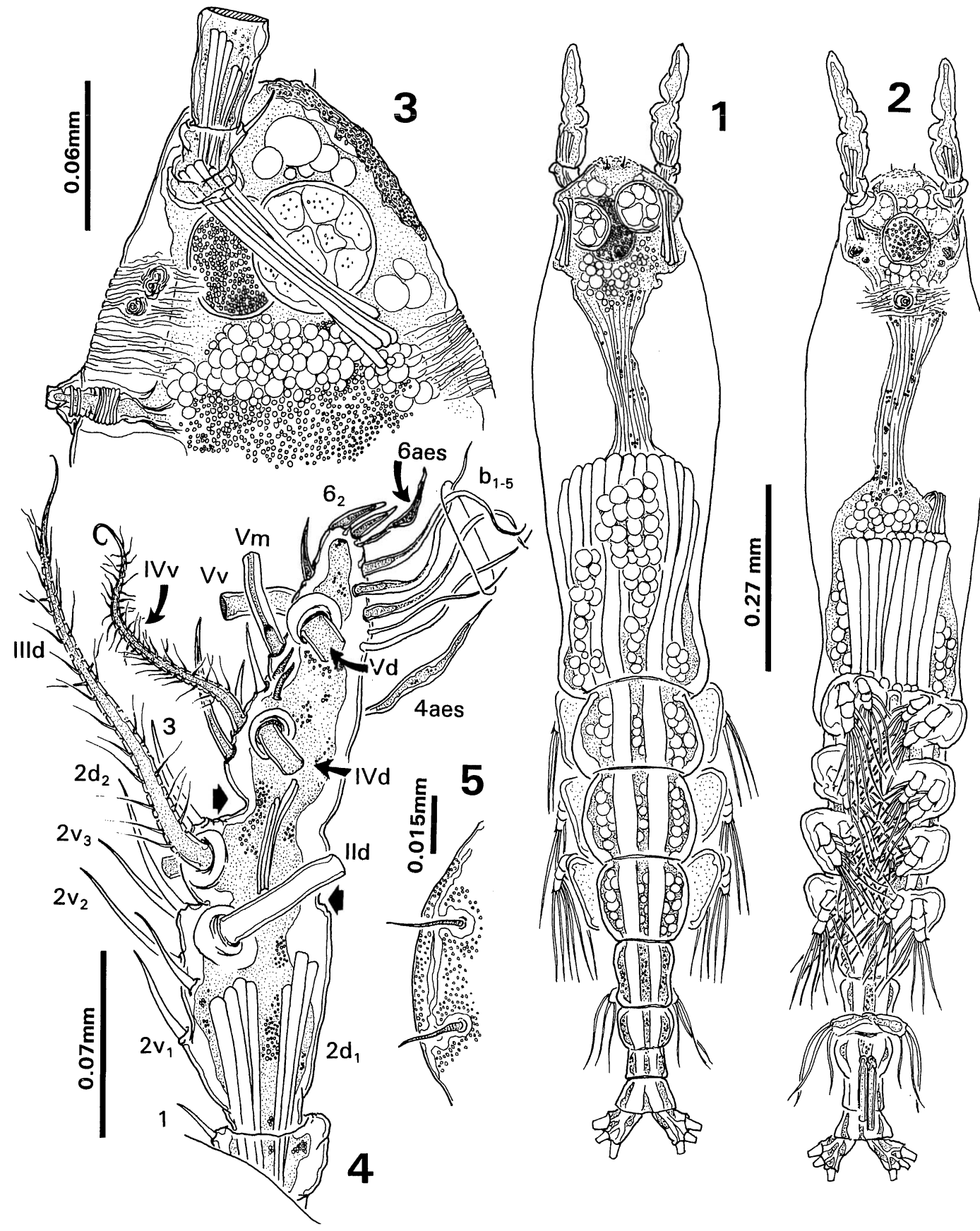

Figures 1-5. Cymbasoma tumorifrons (Isaac) adult female from Zihuatanejo, México. 1, Habitus, dorsal; 2, habitus, ventral; 3, head and oral papilla, lateral; 4, right antennule, dorsal (designation of armature elements follows Grygier and Ohtsuka [1995]); 5, details of cephalic sensillae, dorsal (figure rotated $90^{\circ}$ ). 


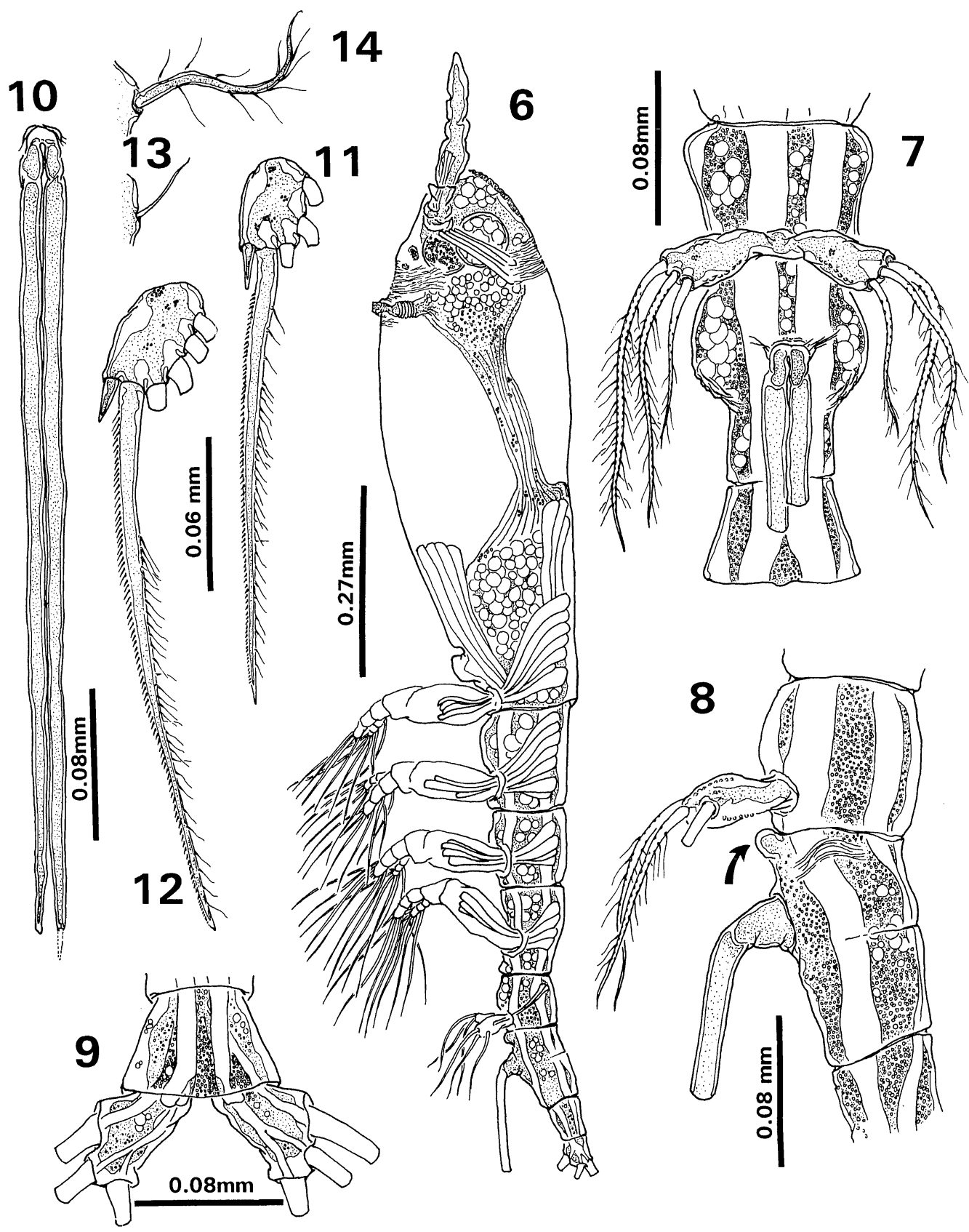

Figures 6-14. Cymbasoma tumorifrons (Isaac) adult female from Zihuatanejo, México. 6, Habitus, lateral; 7, urosome with fifth legs and ovigerous spines, ventral; 8 , same, lateral; 9 , anal somite and furcal rami, dorsal; 10, ovigerous spines, ventral (dotted line indicates suggested length); 11, terminal exopodal segment of left leg 1, anterior; 12, terminal exopodal segment of left leg 3 , anterior; 13, basipodal seta of leg 4; 14, basipodal seta of leg 3 . 
proximally, armed with three lightly setulated setae, innermost $25 \%$ shorter than the outer two. Outer setae reaching about halfway along the anal somite (Figures 7,8), inner short seta not reaching distal margin of genital double somite. Fifth leg inner margins with single, longitudinal row of papillalike cuticular processes (Figures 7,8).

Urosome consisting of three somites: fifth pedigerous, genital double somite (with ovigerous spines), plus the anal somite. Genital double somite largest of urosome, pearshaped, strongly globose on anterior half, with faint suture on dorsal surface. Suture reaching about midway around somite (Figures 7,8$)$. Rounded protuberance present on anterior ventral part of genital double somite, visible in lateral view (Figure 8, arrow). Genital double somite bearing a pair of ovigerous spines, separated at slightly turgent, anteriorly projected base (Figure 8). Ovigerous spines relatively long $(0.5 \mathrm{~mm})$, representing ca. $36 \%$ of total body length. Ratio of lengths of fifth pedigerous and following two somites: $36.1: 44.3: 19.5=100$. Anal somite with diverging margins, outer margins smooth (Figure 9).

Caudal rami subtriangular, with terminal margin wider than proximal one. Approximately 1.2 times longer than wide, bearing three well-developed terminal setae, outermost wider at base than others (Figure 9).

SPECIMENS EXAMINED: Adult female, Zihuatanejo Bay, central coast of the Mexican tropical Pacific $\left(17^{\circ} 38^{\prime} 00^{\prime \prime} \mathrm{N}\right.$, $\left.101^{\circ} 33^{\prime} 30^{\prime \prime} W\right)$, 14 September 1999, plankton sample. Deposited in the ECOSUR zooplankton collection as no. ECO-CHZ.01126. Allotype adult female, Emborios Bay, Aegean Sea, Greece, plankton trawl, surface waters. Vial deposited at the British Museum of Natural History, London, United Kingdom (1974.407.12). Two paratype female specimens, same locality as allotype, vial deposited at the same institution (1974.408.12). The female type specimens were not dissected during examination.

As mentioned by Suárez-Morales (1999), Isaac's (1974) original description of C. $t u$ morifrons was made under the invalid genus Thaumaleus. The name and description of this and other monstrilloid species were presented in a document not considered a valid publication under Committee on Zoological Nomenclature rules (art. 9(11)). Isaac (1975) and later Grygier (1995) stated that names of these species were in fact nomina nuda. These names became available when published by Isaac (1975).

The Zihuatanejo specimen was identified as Cymbasoma tumorifrons based on several characters described by Isaac (1974) and present in the type specimens (Table 1). The main difference between the type specimens and our specimen is the size. However, this is not a factor with strong taxonomic value; several species show very wide size ranges, even up to a factor of two (Isaac 1975). Hence, the size of the Mexican female of this species merely increases the known range of size variation for C. tumorifrons. According to our analysis, the slight differences between the Mediterranean and Mexican specimens are not sufficient to warrant erection of a new taxon; the Mexican specimen is best treated as a female C. tumorifrons.

Considering the setation pattern of female antennules proposed by Grygier and Ohtsuka (1995), it is clear that this species has welldeveloped setation, with almost all setae and spines of the basic monstrilloid pattern. Differences were found between the antennules of the Mexican specimen and those depicted in Isaac's original description. We detected 10 elements ( $\mathrm{IVd}, 4 \mathrm{~d}_{2}, 4 \mathrm{v}_{1-3}, 5, \mathrm{Vv}, 6 \mathrm{aes}, \mathrm{b}_{5}$, $\mathrm{b}_{6}$ ) not included in Isaac's (1974) depiction of the antennular armature of $C$. tumorifrons. The analysis presented here completes the antennular armature set of the female of this species.

Isaac (1974) did not illustrate the swimming legs, and they were only mentioned in the brief description as having the usual monstrillid pattern. In fact, the swimming legs of $C$. tumorifrons have the basic setation pattern described for the group. Some details of leg characters whose taxonomic relevance has not been shown, such as the armature of the outermost terminal spiniform seta of the exopods, are here described and illustrated for the first time. They indeed follow the general pattern as described for other female Cymba- 
TABLE 1

Comparison of Type Specimens of Cymbasoma tumorifrons (Isaac) with the Mexican Specimen

\begin{tabular}{|c|c|c|}
\hline Character & Type Material & Mexican Material \\
\hline Cephalic somite & Lightly reticulated & Same as type \\
\hline Cephalothorax length & Over half the length & 0.55 of body length \\
\hline Position of oral papilla & At 0.16 of way back along cephalothorax & At 0.25 of way back along cephalothorax \\
\hline Antennule relative length & $\begin{array}{l}\text { Almost } 0.20 \text { of total body length; with } \\
\text { three unbranched terminal setae; } \\
\text { terminal inner spine longer than the } \\
\text { outer }\end{array}$ & $\begin{array}{l}0.17 \text { of total body length; otherwise same } \\
\text { as described for type material }\end{array}$ \\
\hline Fifth legs & $\begin{array}{l}\text { Single ramus, armed with three setae, } \\
\text { inner one shorter than outer two } \\
\text { setae }\end{array}$ & Same as described for type material \\
\hline Genital double somite & Pear-shaped & Same as described for type material \\
\hline Ovigerous spines & $\begin{array}{l}0.47 \text { of body length, } 0.9 \text { of length of } \\
\text { cephalothorax }\end{array}$ & $\begin{array}{l}0.44 \text { of body length, } 0.7 \text { of length of } \\
\text { cephalothorax }\end{array}$ \\
\hline Caudal setae & Subrectangular, with three setae & Same as type \\
\hline Eye size & Relatively large & $\begin{array}{l}\text { Same as type, asymmetrically arranged, } \\
\text { probably as result of fixation }\end{array}$ \\
\hline Length of females & $0.76-1.03 \mathrm{~mm}$ & $1.4 \mathrm{~mm}$ \\
\hline
\end{tabular}

soma (Suárez-Morales and Escamilla 1997, Suárez-Morales and Gasca 1998).

The fifth legs basically match the structure shown by Isaac's draft illustration, except that he missed several details. One is the presence of a series of cuticular bumps along the lateral and dorsal margins of the fifth leg lobe; another is the setulation of the fifth leg setae, which is sparse, but present all along the length of the setae.

Based on the collection of the three males and three females from the Aegean in the same plankton trawl, Isaac (1974) assumed that they all belonged to a single species: $C$. tumorifrons. However, this may have been misleading because the only way to link males and females of one monstrilloid species is to find them in the same host or verify that they share distinctive diagnostic characters (Suárez-Morales and Escamilla 1997). Males and females of several species can be collected in the same zooplankton sample, especially in areas where the benthic fauna is diverse. Morphologic characters that may link both sexes include striation of the head (SuárezMorales and Escamilla 1997) and the general structure of the eyes. In both males and females of $C$. tumorifrons the eyes are relatively large.
Another feature whose value to link sexes is yet undetermined is the branching pattern of Grygier and Ohtsuka's (1995) setae $b_{1}-b_{3}$. These are distally branched in male $C$. $t u$ morifrons (Suárez-Morales 1999) and unbranched in the assigned female (Isaac 1974). This difference was not considered relevant by Suárez-Morales and Escamilla (1997) in the determination of conspecificity of males and females of Cymbasoma. Isaac (1974) added the arrangement of these setae as another similarity between the two sexes. The arrangement of these setae is really quite uniform in the group and is thus not a good character to link sexes.

Although the Mexican female seems to represent $C$. tumorifrons, there is the possibility that it belongs to another species. With the evidence currently available, however, we conclude that the Mediterranean male and female type specimens and the Mexican female specimen are best treated as a single species, Cymbasoma tumorifrons.

Little is known about the biogeography of monstrilloid copepods; the apparently restricted distributions of some species are probably due to lack of knowledge or sampling of this group in other areas. This appears to be the case for $C$. tumorifrons, the 
geographic range of which was greatly increased by inclusion of the Mexican specimen. For monstrilloid copepods, one of the least-studied regions is the eastern Pacific. Other species of Monstrilloida reported from the Pacific include Cymbasoma californiense Suárez-Morales, 1999; C. rigidum Thompson, 1888; Monstrilla capitellicola Hartman, 1961; $M$. gibbosa Suárez-Morales \& PalomaresGarcía, 1995; $M$. belgolandica Claus, 1863; $M$. longiremis Giesbrecht, 1892; M. spinosa Park, 1967; and M. wandelii Stephensen, 1913 (Park 1967, Grygier 1995, Razouls 1996, SuárezMorales and Vásquez-Yeomans 1996). The monstrilloid copepod fauna in these areas is likely to increase with better sampling and improved understanding of copepod variation.

\section{ACKNOWLEDGMENTS}

The type specimens examined were kindly sent to us by Ann Morgan, The Natural History Museum, London. Geoff Boxshall (NHM, London) made available the Ph.D. thesis of Michael J. Isaac, published by the University of Wales at Swansea.

\section{Literature Cited}

Grygier, M. J. 1994 [dated 1993]. Identity of Thaumatoessa (= Thaumaleus) typica Krøyer, the first described monstrilloid copepod. Sarsia 78:235-242.

. 1995. Annotated chronological bibliography of Monstrilloida (Crustacea: Copepoda). Galaxea 12:1-82.

Grygier, M. J., and S. Ohtsuka. 1995. SEM observation of the nauplius of Monstrilla bamatapex, new species, from Japan and an example of upgraded descriptive standards for monstrilloid copepods. J. Crustacean Biol. 15:703-719.
Isaac, M. J. 1974. Studies on planktonic arthropods. Ph.D. thesis, University College of Swansea, Wales, United Kingdom.

-1975. Copepoda, Suborder: Monstrilloida. Fiches Identif. Zooplancton 144/ 145: 1-10.

Park, T. S. 1967. Two unreported species and one new species of Monstrilla (Copepoda: Monstrilloida) from the Strait of Georgia. Trans. Am. Microsc. Soc. 86:144-152.

Razouls, C. 1996. Diversité et répartition géographique chez les copépodes pélagiques. 2.-Platycopioida, Misophrioida, Mormonilloida, Cyclopoida, Poecilostomatoida, Siphonostomatoida, Harpacticoida, Monstrilloida. Ann. Inst. Oceanogr. 72:1-149.

Suárez-Morales, E. 1999. Redescription of the male of Cymbasoma tumorifrons (Isaac, 1975) from the Mediterranean Sea (Copepoda: Monstrilloida). Arthrop. Selecta 8 (1): $67-71$.

Suárez-Morales, E., and J. B. Escamilla. 1997. An undescribed monstrilloid copepod (Copepoda: Monstrilloida) from the northern Yucatan Peninsula, Mexico. Bull. Mar. Sci. 61:539-547.

Suárez-Morales, E., and R. Gasca. 1998. Cymbasoma bowmani n. sp., a new monstrilloid (Copepoda: Monstrilloida) from a Caribbean reef, with notes on species variation. J. Mar. Syst. 15:433-439.

Suárez-Morales, E., and N. Riccardi. 1997. Redescription and first record of Cymbasoma tenue (Isaac, 1975) (Copepoda: Monstrilloida) in the Mediterranean Sea. Proc. Biol. Soc. Wash. 110:99-106.

Suárez-Morales, E., and R. Vásquez-Yeomans. 1996. On Monstrilla spinosa Park, 1967 (Copepoda, Monstrilloida) in the eastern Pacific. Crustaceana (Leiden) 69:288-294. 